\title{
Modelling, sensitivity and exergy analysis of triple-pressure heat recovery steam generator
}

\author{
Suha Orçun Mert, ${ }^{1,2 *}$ Zehra Özçelik, ${ }^{3}$ Ceyda Kök ${ }^{2}$ \\ ${ }^{1}$ İskenderun Technical University (ISTE), Department of Mechanical Eng., Iskenderun, Hatay, Turkey, \\ orcunmert@gmail.com, ORCID: 0000-0002-7721-1629 \\ 2 İskenderun Technical University (ISTE), Institute of Energy, Iskenderun, Hatay, Turkey, ORCID: 0000-0002-5536-3488 \\ ${ }^{3}$ Ege University, Department of Chemical Engineering, İzmir, Turkey, ORCID:0000-0001-9470-4161
}

\section{A B S T R A C T}

Related to the increasing demand for environmental pollution and electrical energy, combined cycle power plants (CCPP) are increasingly important. So, It is necessary that increasing the performance of power plants, reducing carbon emissions and rising energy production. Any change related to the heat recovery steam generator design is important for essential components of the CCPP because of directly affects the performance of it. In this study, it has explained that the modelling, sensitivity and exergy analysis of a Heat Recovery Steam Generator (HRSG) in a CCPP. In the analyzes, three-pressure HRSG was modelled with the Aspen Plus simulation program. In addition to, sensitivity analyzes were done and evaluated. Also, energy and exergy analyzes were done for each component in the CСPP.

\author{
ARTICLE INFO \\ Research article \\ Received: 11.09 .2020 \\ Accepted: 13.12 .2020 \\ Keywords: \\ Combined cycle power \\ plant, \\ heat recovery steam \\ generator, \\ Sensitivity Analysis, \\ Exergy Analysis, \\ ASPEN Plus \\ ${ }^{*}$ Corresponding author
}

\section{Introduction}

Electric energy is a form of energy that plays an important role in sustainable development. With the increase of population and industrial use, the demand for electrical energy in developed and developing countries is increasing. Electricity; is produced in power plants where fossil fuels such as oil, natural gas and coal are used and chemical energy is converted into electrical energy. However, the use of fossil fuels causes for variety problems, such as global warming, acid rains and thinning of the ozone layer. Therefore, many energy scenarios have been realized in order to increase the performance in power plants and use clean energy. These energy scenarios include fossil fuel technologies with low environmental impact, the use of renewable energy sources and efficient use of all energy sources. The CCPP, have a significant impact on the energy scenario, due to provides sufficient load response, good flexibility at different stages, good thermal efficiency and low environmental impact compared to other fossil fuels.

CCPP consists of three main devices. These are gas turbine, heat recovery steam turbine and steam turbine generator. Gas turbine compresses the air and mixes with high temperature fuel. And mixtures of hot air and fuel moves throught with the blades of gas turbine, causing the blades to rotate. Fast rotating turbine drives the generator that converts some of the energy into electricity. The Heat Recovery Steam Generator (HRSG) generates steam from the exhaust heat of the gas turbine and transmits it to the steam turbine. The steam turbine generator produces additional electricity from excessive heat exhaust.

In conventional power plants, turbines work efficiency of $33 \%$. But, this efficiency is $50 \%$ or more for CCPP. So it shows that they burn half a fuel less than traditional power plants to produce the same amount of energy. According to literature, work efficiency in CCPP is increased from 30\% to $90 \%$ to produce useful heat and electricity from the same fuel source at the same time. Thus, while producing fewer emissions from traditional plants, it contributed to the economy by using resources more efficiently [1].

HRSG is a crucial component for meeting both the requirements of the steam turbine and the constraints of the 
gas turbine. So, it should be designed to maximize the transferred heat, ensure thermal efficiency and minimize cost. Any changes in HRSG design directly affects CCPP efficiency, net power and production costs. Various gas turbines are available for different operating conditions, such as exhaust gas and back pressure. For selected gas turbine, steam turbine and HRSG must work in accordance. Also, efficiency of the steam cycle largely depends on the HRSG design.

Operating at a temperature of about $650{ }^{\circ} \mathrm{C}$ and 13-20 MPa pressure, HRSG recovers heat from the gas turbine exhaust to produce steam. Although flow loop systems developed, heat recovery steam systems are implemented under subcritical conditions [2].

Advanced multi-pressure HRSGs are preferred due to provide high efficiency despite their high cost. Thermal efficiency is being increased by adding two or three parallel steam streams for high, intermediate and low pressure stages of steam turbines.

HRSG has been studied in many ways in the literature in recent years. Pressure level selection [3], modeling and design [4], effect of heat transfer surface on thermal performance [5] extensively studied. Also, the application of the genetic algorithm in a structural sense [6], application of thermodynamic and thermo-economic approaches for parameter design [7] has attracted attention in recent years. Exergy, environmental and economic analysis has been performed for CCCP. [8].

Today, HRSG with three pressure levels combining steam and gas turbines is considered the latest technology. Since HRSG has a major impact on the thermal efficiency of the steam cycle, many studies have been conducted on this subject $[9,10]$. Pelster et al. compared CCPP efficiency results of double and triple pressure HSRGs and steam reheat models [11]. Optimization of single, double and triple pressure HRSGs to improve heat recovery and exergy efficiency in CCPPs made by Sirinas et al. [12]. Ahmadi et al. made the thermodynamic analysis of double pressure HSRG. They used the multi-purpose optimization method to find the best design parameters. The functions considered for optimization are cost and exergy efficiency [13]. Three pressure CCGT optimizations were carried out by Alus and Petrovi. While optimizing Alus and Petrovi, they aimed to minimize the cost of electricity generation at the CCGT plants [14]. Alobaid et al. with real power plant data, three pressure HRSGs were created in detail in a digital model with Aspen Plus. Also these authors evaluated the control structure with Aspen Plus Dynamics [15]. Ali et al. performed energy and exergy analysis with triple pressure HRSGs. As a result of calculating the exergy destructions for each component of the HRSG, it was determined that high pressure components have higher exergy destruction than low pressure components [16].
Moosavi et al. In the hot summer, HRSG proposed a new method to improve performance. As a result, HSRG exergy destruction increased due to the high temperature difference in the flows, despite the increase in net power [17]. Boyaghchi et al. used sensitivity analysis to examine the effects of compressor pressure ratio. They observed that thermal and exergy efficiency increased when the compressor pressure ratio increased [18].

In this study; exergy analysis of the HRSG that three levels of pressure are applied has been comprehensively analyzed. Energy and exergy analyzes were performed for each component in CCPP. At the same time, the three-level HRSGs system was modeled with Aspen Plus software and sensitivity analysis was performed.

\section{Modeling and simulation}

\subsection{Modeling in ASPEN PLUS}

Advanced System for Process Engineering software (ASPEN) is used to model advanced system power plants. It is a software program developed in 1981 in collaboration with the Massachusetts Institute of Technology (MIT) and the United States Department of Energy [19].

ASPEN Plus simulation program; analyze the behavior of the process by making use of engineering relations such as chemical balance, mass and energy balances, reaction kinetics. True plant analysis can be simulated thanks to realistic operating conditions and thermodynamic data. This program helps to increase the efficiency of existing facilities and design better facilities.

ASPEN Plus; used to analyze fluid configurations and find new alternatives. In addition, results can be obtained in the form of PFD-style drawings, reports, graphs and spreadsheets.

\subsection{Exergy Analysis}

The first law of thermodynamics is required in the analyzes to evaluate energy efficiency. But, it does not give a complete conclusion about the potentials and limitations of use of various components of energy system analyzed by this law. This situation, impairs compatibility in design and manufacturing. Exergy is the maximum amount of energy it can absorb from any energy source.

Exergy or available energy refers to the most useful work a system can do when it comes to balance with its environment. However, the second law of thermodynamics, or exergy analysis, gives better results in the design and performance analysis of energy systems. Therefore, exergy is a measure of the system's potential to do business for a particular environmental state. Exergy analysis has gained great importance in the evaluation and design of thermal systems. 
Exergy is not generally protected. Conversely, it disappears because of the irreversible situations in the system. In light of these, a general exergy analysis reveals how much energy loss occurs in the system and where it occurs. Thus, thermodynamic inefficiencies within the system are revealed. [20].

\subsection{Modeling Sensitivity Analysis}

Sensitivity analysis is performed to measure the effects of mathematical modeling or changes in system parameters on system outputs or performance. In short; sensitivity analysis is used to distribute changes in the outputs of a system to uncertain different sources in its inputs. One of the system parameters is changed at a certain rate while other parameters are fixed. And after the system is started, the percentage change of the predetermined system parameters is observed. Sensitivity analysis is used to investigate the robustness, accuracy of model results and to understand. Also, it examines the relationships between input parameters and performance of a system or model. Monitoring the change of model parameters is very important in determining the system inputs, which leads to uncertainty in system performance. Therefore, sensitivity analysis is given importance to eliminate the uncertainty of the parameters and increase the reliability of the system [21].

While responsiveness blocks have no effect on basic simulation, they provide additional information to the basic case results. Simulation, on the other hand, operates completely independently of sensitivity analysis. Multiple variable precision blocks for each value combination form a row in the sensitivity table. And these blocks form loops so that they are evaluated only once for each line in the sensitivity table. Aspen Plus program sorts the blocks automatically.

\section{Case study}

Figure 1 shows typical triple pressure HRSG. HRSGs are multi-pressurized with channel firing and other features, and can become more complex. This diagram shows main gas, steam and condensate flows, HRSG surfaces and steam drums. Flue gas comes from combustion turbine and enters HRSG, and then decreases its temperature by passing through heater, reheater, drum evaporator surfaces and economizer. The condensate comes from the combined cycle condenser and flows into the economizer drum. This steam first flows to the superheater then to high-pressure turbine. After high pressure turbine, it flows back to heater and intermediate pressure turbines. Important design parameters of HRSG are pinch points and approach temperatures. Reducing temperature helps increase cycle efficiency. Also, it includes optimization, complex heat transfer calculations and steam cycle heat balances to avoid operational problems.
Modeling a thermal system consists mainly in the calculation of its operating variables, in principle for a given stationary state. The detailed modeling and simulation of the HRSG is a complex problem, depending on several variables.

The operating parameters can be determined by means of both a thermodynamic and exergetic analysis [22]. ASPEN Plus was used for the calculation and evaluation of all results. Mass, energy, exergy and design equations and thermodynamic properties were enabled using related operating variables. These calculations were done for a steady state process at $15 \mathrm{C}$ and $27 \% \mathrm{RH}$ and the content of the used fuel gas was $82 \% \mathrm{CH}_{4}, 10 \% \mathrm{C}_{2} \mathrm{H}_{6}, 2.2 \% \mathrm{C}_{3} \mathrm{H}_{8}, 2 \% \mathrm{C}_{4} \mathrm{H}_{10}$, $0.8 \% \mathrm{C}_{5} \mathrm{H}_{12}, 2 \% \mathrm{CO}_{2}, 1 \% \mathrm{~N}_{2}$ as molar basis. Figure 1 shows the configuration of the HRSG designed with the ASPEN Plus Simulation Program.

\subsection{Exergy Calculations}

As with energy, exergy in any current can be divided into different components. When nuclear effects, magnetism, electricity, and surface tension are ignored, exergy $(E)$ :

$$
E=E_{k}+E_{p}+E_{p h y}+E_{c h}
$$

It is defined as. In this equation, additional kinetic exergy corresponds to Ep potential exergy, Eph physical exergy, $\mathrm{E}_{\mathrm{ch}}$ chemical exergy. Kinetic and potential exergy are not taken into account. Physical exergy is defined as the maximum work achieved when a substance with a certain temperature and pressure in a current reaches the reference state through physical processes involving heat processes. Chemical exergy arises from the difference between the content of the current and the reference state [20].

$$
\begin{gathered}
\mathrm{E}_{\text {phy }}=\left(\mathrm{H}_{1}-\mathrm{T}_{0} \mathrm{~S}_{1}\right)-\left(\mathrm{H}_{0}-\mathrm{T}_{0} \mathrm{~S}_{0}\right) \\
\mathrm{E}_{\mathrm{ch}}=\mathrm{E}_{\mathrm{ch}}^{\mathrm{o}}+\Sigma(\mathrm{x} \ln (\mathrm{x}))
\end{gathered}
$$

In an isolated steady control volume, exergy balance occurs as follows:

$$
E_{i}=E_{0}+W+E_{D}
$$

Where, $E_{\mathrm{i}}$ exergy entering the system, exergy exiting from the $\mathrm{E}_{\mathrm{o}}$ system, $\mathrm{W}$ is the transfer of work between the system and the environment, and $E_{D}$ is the exergy destroyed in the system. Considering these techniques, exergy calculations were made in gas turbines, waste heat boilers and steam turbines on one of the two energy blocks in the combined cycle power plant. The reference state was chosen for this study in general atmospheric content $\left(21 \% \mathrm{O}_{2}, 79 \% \mathrm{~N}_{2}\right)$ at $20^{\circ} \mathrm{C}$ and $1 \mathrm{~atm}$. Figure 2 shows basic combined cycle schematization. 


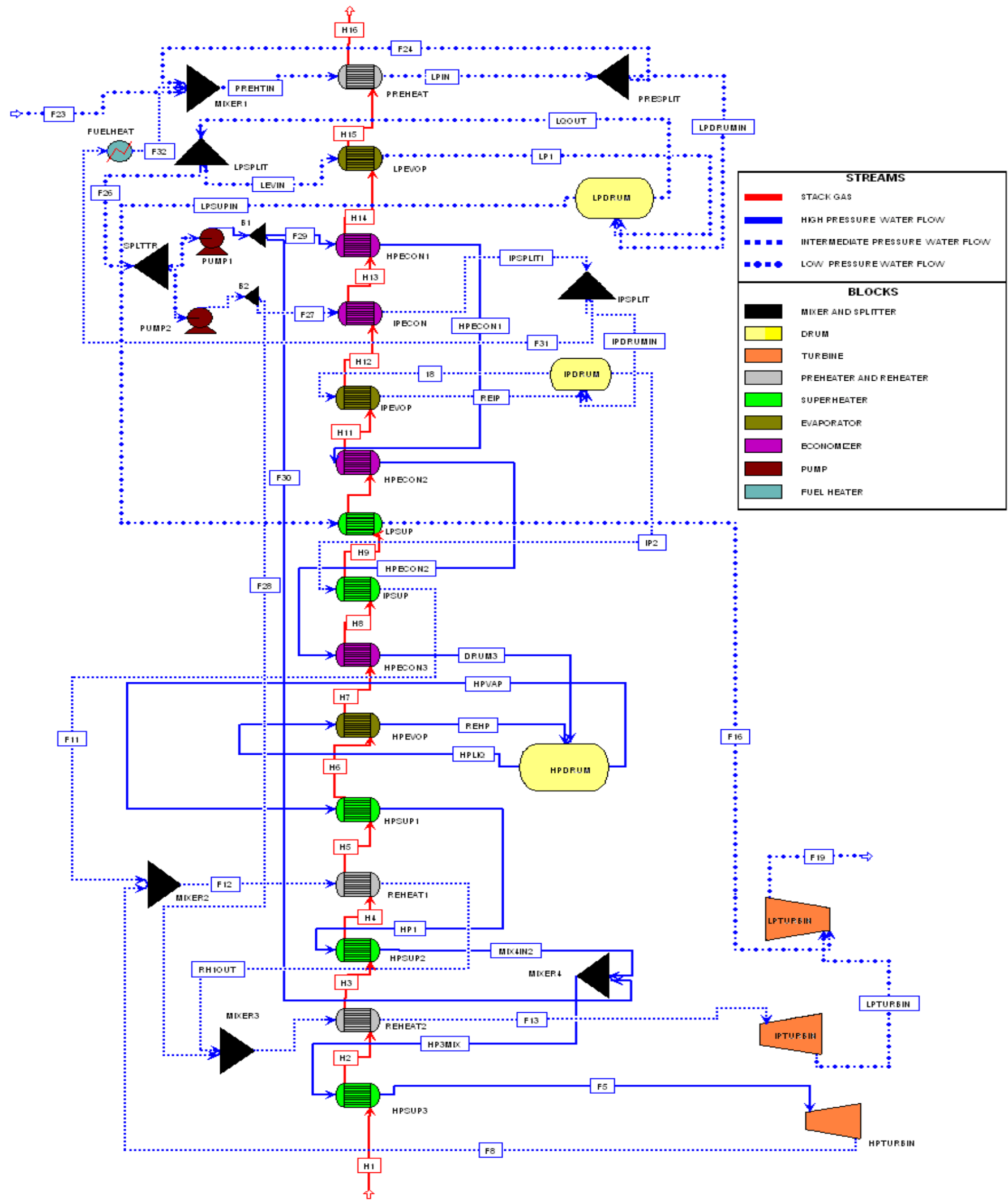

Figure 1. Heat Recovery Steam Generator Configuration 


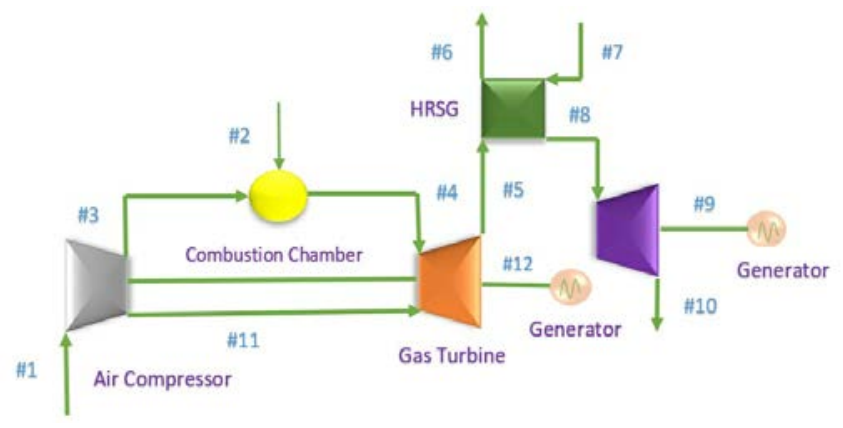

Figure 2. Basic Combined Cycle schematization

\subsubsection{Gas Turbine}

Gas turbine basically consists of three parts. These are; Compressor for air to be used in combustion and cooling; combustion chamber, section where the fuel is burned with compressed air and turbine.

Compressor: The air to be used in the combustion chamber is compressed in the compressor. The incoming air comes in atmospheric conditions $(\mathrm{T}=293.15 \mathrm{~K}, \mathrm{P}=1 \mathrm{~atm})$. The compressor works with 1/14 compression ratio. Equations (5) and (6) are used in compressor calculations.

$$
\begin{aligned}
& E_{1}+E_{11}=E_{3}+E_{D} \\
& \eta=\left(E_{3}-E_{1}\right) /\left(E_{11}\right)
\end{aligned}
$$

Combustion Chamber: It is accepted that full combustion occurs in the combustion chamber. Temperature, pressure and flow values were taken under operating conditions. The exergy of the fuel was calculated using (3) and (4). Calculations in the combustion chamber are made by using equations (7) and (8).

$$
\begin{gathered}
E_{3}+E_{2}=E_{4}+E_{D} \\
\eta=E_{4} /\left(E_{3}+E_{4}\right)
\end{gathered}
$$

Turbine: The turbine has an expansion up to approximately atmospheric pressure (1,044 bar), and the outlet temperature

\begin{tabular}{|c|c|c|c|c|c|c|c|}
\hline & & $\begin{array}{c}\text { Energy Transfer } \\
\text { Rate } \\
\text { /Hot and Cold } \\
\text { Stream [MW] } \\
\end{array}$ & $\begin{array}{c}\text { Gas side } \\
\text { Enthalpy } \\
\text { change } \\
\text { [MW] }\end{array}$ & $\mathbf{T}_{\text {gas i }}[\mathbf{K}]$ & $\begin{array}{c}\mathbf{T}_{\text {gas o }} \\
{[\mathbf{K}]}\end{array}$ & $\begin{array}{c}\mathbf{T} \\
\text { steam i } \\
{[\mathbf{K}]}\end{array}$ & $\mathbf{T}_{\text {stm o }}[\mathbf{K}]$ \\
\hline Unit 14 & Superheater HP & 954.9 & 954.9 & 899.0 & 861.9 & 763.8 & 841.5 \\
\hline Unit 8 & Preheater & 2832.5 & 2832.5 & 861.9 & 797.6 & 713.0 & 838.3 \\
\hline Unit 13 & Superheater HP & 1081.6 & 1081.6 & 797.6 & 757.7 & 683.0 & 767.9 \\
\hline Unit 7 & Preheater & 2492.0 & 2492.0 & 757.7 & 696.7 & 618.3 & 739.0 \\
\hline Unit 12 & Superheater HP & 1037.1 & 1037.1 & 696.7 & 657.2 & 598.7 & 683.0 \\
\hline Unit 11 & Evaporator HP & 4.6 & 4.6 & 657.2 & 654.6 & & \\
\hline
\end{tabular}
is $900 \mathrm{~K}$, which is the operating condition. Input features are taken as $\mathrm{T}=1570 \mathrm{~K}$ and $\mathrm{P}=14 \mathrm{barg}$.

Table 1. The temperature and enthalpy changes in HRSG

$$
\begin{aligned}
& \mathrm{E}_{4}=\mathrm{E}_{11}+\mathrm{E}_{5}+\mathrm{E}_{6} \\
& \eta=\left(E_{11}+E_{6}\right) /\left(E_{4}-E_{5}\right)
\end{aligned}
$$

\subsubsection{Heat recovery steam generator}

Hot steam is produced at three different pressures in HRSG. These are LP (4.3 bar), IP (25 bar), HP (122 bar). For this, 15 different modules with different tasks are used. These modules work as heat exchangers or evaporators. These modules and in general, calculations for HRSG (11) and (12) were used.

$$
\eta=\left(\begin{array}{c}
E_{5}+E_{7}=e_{6}+E_{8} \\
\left(E_{7}-E_{8}\right) /\left(e_{6}-E_{5}\right)
\end{array}\right.
$$

\subsubsection{Steam Turbine}

There are three separate steam turbines operating on the same axle was used in the analysis for these. $838 \mathrm{~K}$ and 122 bar for $\mathrm{HP}$, whose input conditions are operating values, $835 \mathrm{~K}$ for IP and 25.5 bar and finally $564 \mathrm{~K}$ and 5 bar for LP were taken. Output values are $624 \mathrm{~K}$ for HP and $566.5 \mathrm{~K}$ for 29.4 bar IP and $314 \mathrm{~K}$ and 0.0077 bar for 5 bar IP.

\section{Results}

\subsection{Exergy Analysis Results}

As a result of the calculations, the exergy values, exergy losses and efficiency at the inputs and outputs of the combined cycle equipment analyzed were done.

Table 1 assumes that the temperature does not change horizontally for HRSG gas side and temperature and enthalpy change values are calculated using energy balances. Gas side nomenclature is used for combustion products. In the combustion chamber, full combustion is accepted and the content of combustion products is $0,11 \mathrm{O}_{2}$ in mole fraction; $0.78 \mathrm{~N}_{2}$; It was calculated as $0.04 \mathrm{CO}_{2}$ and $0.07 \mathrm{H}_{2} \mathrm{O}$ and used. In energy calculations, combustion products were considered ideal and enthalpy and entropy values were calculated under these conditions. 


\begin{tabular}{cccccccc} 
Unit 15 & Economizer HP & 885.4 & 885.4 & 654.6 & 617.9 & 547.7 & 596.7 \\
Unit 6 & Superheater IP & 151.1 & 151.1 & 617.9 & 602.7 & 496.0 & 583.5 \\
Unit 3 & Superheater LP & 351.0 & 351.0 & 602.7 & 579.5 & 424.0 & 559.4 \\
Unit 10 & Economizer HP & 772.6 & 772.6 & 579.5 & 545.3 & 498.9 & 547.7 \\
Unit 5 & Evaporator IP & 0.1 & 0.1 & 545.3 & 544.9 & & \\
Unit 4 & Economizer IP & 202.2 & 202.2 & 544.9 & 527.2 & 420.2 & 490.0 \\
Unit 9 & Economizer HP & 1758.7 & 1758.7 & 527.2 & 474.9 & 422.2 & 498.9 \\
Unit 2 & Evaporator LP & 0.2 & 0.2 & 474.9 & 474.4 & & \\
Unit 1 & Preheater & 3521.6 & 3521.6 & 474.4 & 401.0 & 333.0 & 416.0 \\
\hline
\end{tabular}

Table 2 shows the exergy changes on the gas side and steam side in the modules. In general, exergy losses arising from heat transfer can occur, but the large differences calculated may have occurred from the acceptance of ideal gas conditions in the calculations of the gas side.
Another high loss is seen in HRSG. However, as mentioned earlier, this value was high due to calculation methods. In fact, this value is expected to be $3-5 \%$.

Table 3. The efficiency and loss values

Table 2. The exergy changes $\quad$ Loss for

\begin{tabular}{|c|c|c|c|c|c|c|c|c|c|c|c|c|c|}
\hline Units & 1 & 2 & 3 & 4 & 5 & 6 & 7 & 8 & 9 Unit10 & 1Efficign & $y 13^{\text {Loss } 14}$ & (E) $15 \%$ & a Block \\
\hline Gas side [MW] & $\begin{array}{l}71, \\
8\end{array}$ & 1,3 & $\begin{array}{l}16, \\
0\end{array}$ & $\begin{array}{l}14, \\
7\end{array}$ & 1,7 & $\begin{array}{l}11, \\
1\end{array}$ & $\begin{array}{l}35 \\
9\end{array}$ & $\begin{array}{l}36, \\
6\end{array}$ & $\begin{array}{c}\text { 44, } 26, \\
\text { Cempreşor }\end{array}$ & $\begin{array}{rr} & 29, \\
2,0 & 73.6\end{array}$ & $36,66.421,8$ & $22, \bar{\oplus}, 0$ & $\begin{array}{c}\text { (EF) \% } \\
2.0\end{array}$ \\
\hline $\begin{array}{l}\text { Water / Steam } \\
\text { Side[MW] }\end{array}$ & $\begin{array}{l}11, \\
2\end{array}$ & 1,0 & 1,2 & 1,1 & 0,7 & 1,0 & $\begin{array}{l}13, \\
5\end{array}$ & $\begin{array}{l}18, \\
0\end{array}$ & $\begin{array}{l}\text { Turbine } \\
8,9 \text { CC 7,3 } \\
\text { HRSG }\end{array}$ & $\begin{array}{r}93.2 \\
1,1 \quad 71.9 \\
38.9 \\
38.3\end{array}$ & $\begin{array}{c}6.8 \\
10,28.19,6 \\
61.7\end{array}$ & $\begin{array}{l}3.0 \\
30.95,6 \\
22.4\end{array}$ & $\begin{array}{c}3.0 \\
30.5 \\
22.4\end{array}$ \\
\hline \multirow{5}{*}{\multicolumn{8}{|c|}{$\begin{array}{l}\text { Combustion products entering HRSG, as can be seen in Figure } \\
3 \text {, lose their exergy during HRSG and their temperature } \\
\text { decreases. The final value reveals the magnitude of the exergy } \\
\text { lost with the combustion products coming out of the } 123 \mathrm{MW}\end{array}$}} & & HP St. Turbine & 96.4 & 3.6 & 0.2 & 0.1 \\
\hline & & & & & & & & & IP St. Turbine & 93.7 & 6.3 & 0.7 & 0.4 \\
\hline & & & & & & & & & LP St. Turbine & 72.6 & 27.4 & 3.4 & 1.7 \\
\hline & & & & & & & & & Chimney & & & 12.3 & 12.3 \\
\hline & & & & & & & & & Overall & 28.52 & 71.5 & 74.5 & 72.3 \\
\hline
\end{tabular}
the chimney outlet temperature value cannot be reduced too much against the condensation risk of water vapor in the combustion products mixture.

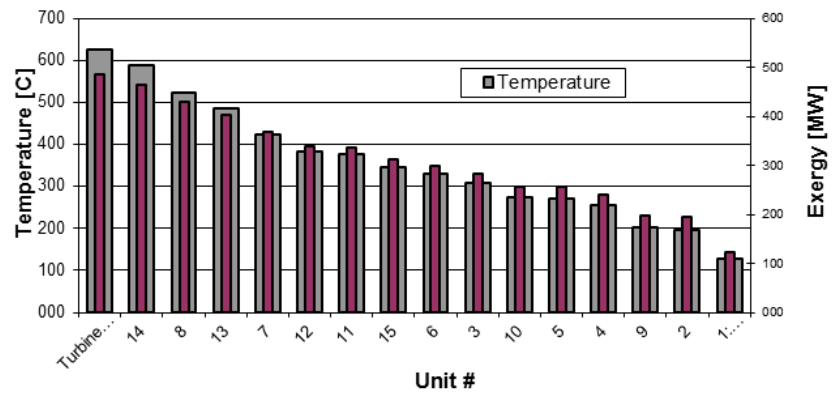

Figure 2. The Exergy and Temperate Change Through the HRSG

After the exergy calculations, exergy efficiency calculations and exergy losses are calculated in comparison to fuel exergy and are shown in Table 3. As can be seen, the highest exergy loss occurs in the combustion chamber. This value complies with the source values and continues to be a general problem of power plants. The improvements that can be made in this section will affect the total efficiency at a high rate and will support the more efficient use of energy, which is the problem of our age.

\subsection{Sensitivity Analysis Results}

Figure 4 shows the produced power of three different pressure steams versus inlet water flowrate. At the same range intermediate pressure steam production is higher that the others. The second axis on the same graph is the chimney outlet temperature versus water flow rate graph. According to this result, high water flowrates are reduced the outlet gas temperature. So, steam production increases simultaneously.

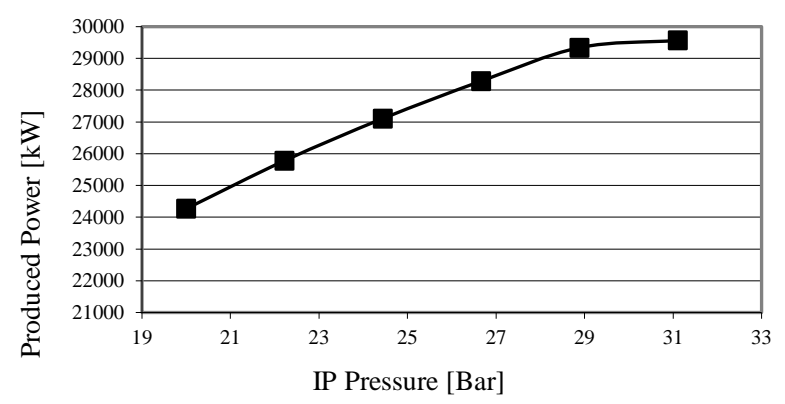

Figure 4. Effect of water inlet flowrate on the produced power and outlet gas temperature 
The main results of this study is the produced power amounts when changing the pressures for different type of steams. Figure 5 shows how the intermediate pressure vapor cavities affect the amount of power generated. The result showed that the production amount remained constant after the amount of generated power increased to 29 bar. For electricity generation, the upper middle pressure range can be determined as 29 or 300 bar.

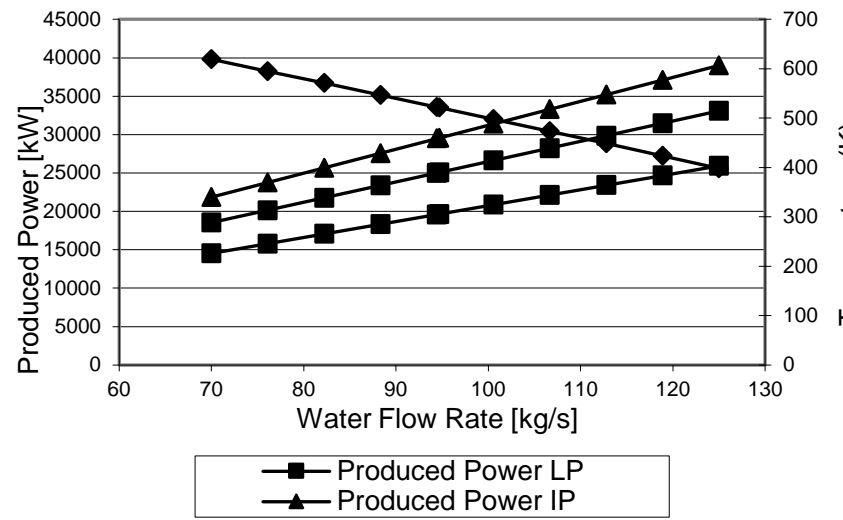

Figure 5. Variation of IP steam pressures on the produced power

The effect of HP steam pressure for the produced power is given in Figure 6. It is seen that with increasing the pressure rises the amount of power produced. The upper limit can be defined from users considering the efficiency of other units.

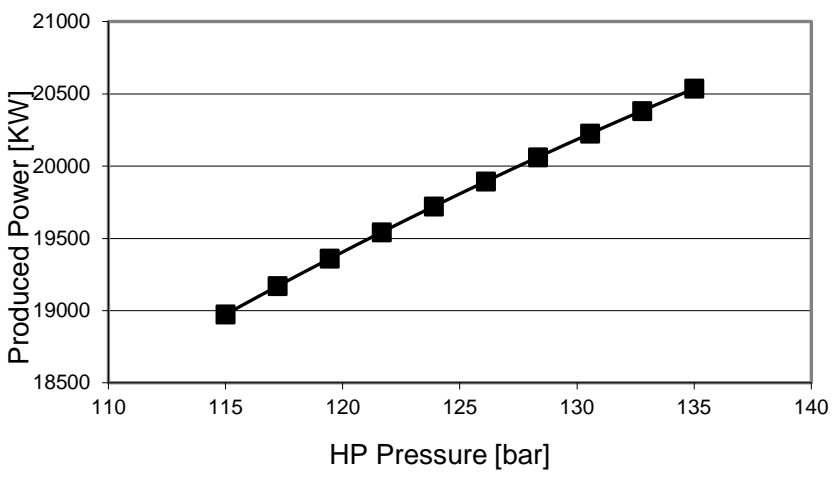

Figure 6. Variation of HP steam pressures on the produced power

Figure 7 shows that the variation of LP steam pressures on the produced power. Different behavior can be observed for this type of steam. Up to 5.5 bar, produced power amount increases, between 5.5 and 6 bar, small amount decreases, then produced power amount is constant. Using these sensitivity results, definite ranges for the system is selected.

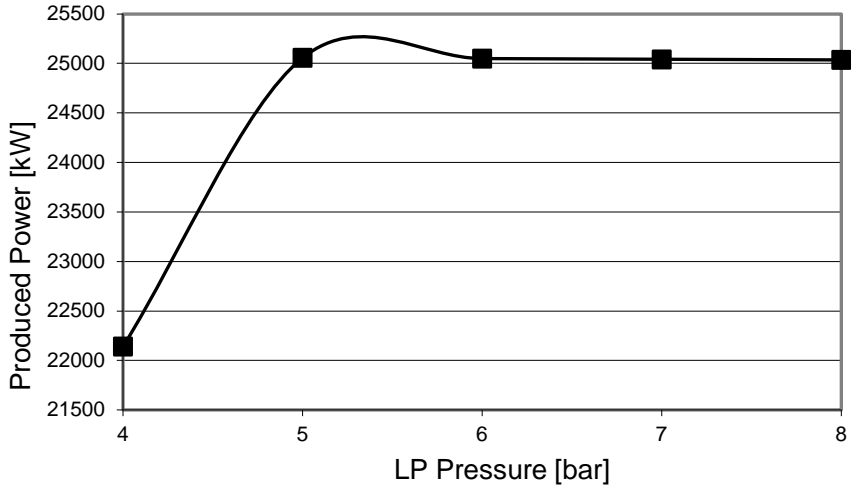

Figure 7. Variation of LP steam pressures on the produced power

Figure 8 shows the effect of LP drum vapor fraction on the produced power and outlet gas temperature. What the lines represent is shown in Figure 1.

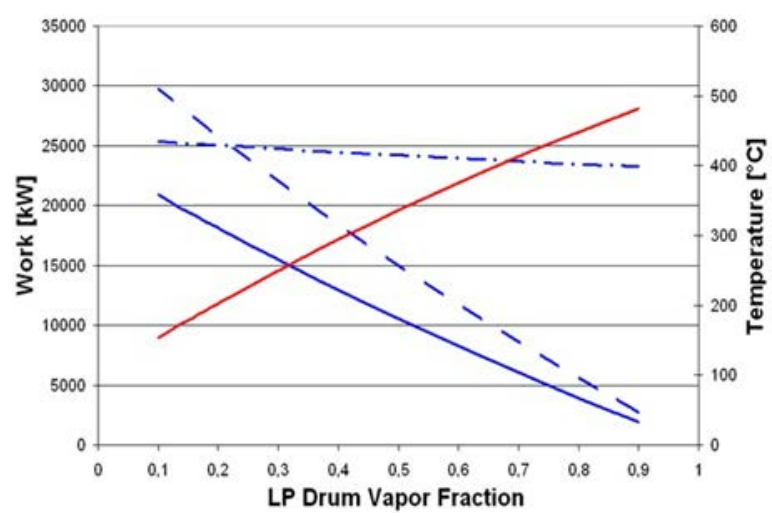

Figure 8. Effect of LP drum vapor fraction on the produced power and outlet gas temperature

\section{Conclusion}

In this study modelling, sensitivity and exergy analysis of a HRSG in a CCPP has been applied. The Three-pressure HRSG was modelled with Aspen Plus simulation program and sensitivity analysis was performed. At the same time, energy and exergy analyzes were made for each component in the CCPP.

A careful evaluation of processes using the concept of exergy enables us to identify the source of inefficiencies. By identifying the most wasteful processes, we are able to redesign the system to achieve the maximum possible savings. Often these improvements can lead to considerable savings.

From the results it is clear that the exergy and temperature of the hot gases in the HRSG decreased throughout the pot. In addition, a significant amount of exergy is transferred to the water/steam system. At the same time, exergy change has been shown depending on different aspects of HRSG. According to this result, it is understood that the exergy lost 
on the gas side is not completely transferred to the water/steam side, but disappears.

The main reason of the losses in combustion chamber is raised from the relatively low firing temperature and if the construction material will resist much high temperature the efficiency of the system will rise.

Moreover the loss in the HRSG is causing from the heat transfer from combustion gases to water/Steam system and also the loss in the chimney is caused from the temperature of nearly $100^{\circ} \mathrm{C}$. But this temperature cannot be pulled down since the combustion gases contains considerable amount of water vapor and if the temperature is allowed to be lower than $100^{\circ} \mathrm{C}$ condensation will occur and the system will fail so this loss is a compulsory one.

So by the exergy analysis it is seen that the exergy destruction (energy loss) is occurs at the combustion chambers with $30 \%$, the HRSG with $22 \%$ and from the chimney with $12,4 \%$. So, the efficiency of the power plant mostly depends on the efficiency of these equipments so any improvement on these equipments will increase the overall efficiency of the plant noteworthy.

It is seen that the effect of HP and IP pressure is more crucial from the produced power point of view from sensitivity analysis whereas the exergy efficiency reaches $28.2 \%$ overall. The tendency of the gaining higher efficiencies are still in the scope of the researchers and engineers.

\section{References}

[1]. Kole A., "A review and study on advanced control and automation functions and future control for a modern combined cycle power plant", 2016 International Conference on Intelligent Control, Power and Instrumentation, (2017), 215-220.

[2]. Rackley S.A., "Carbon capture from power generation. In: Carbon Capture and Storage" (2017).

[3]. Nadir M., Ghenaiet A., "Thermodynamic optimization of several (heat recovery steam generator) HRSG configurations for a range of exhaust gas temperatures" Energy, (2015),685-695.

[4]. Dumont M.N., Heyen G., "Mathematical modelling and design of an advanced once-through heat recovery steam generator", Computers and Chemical Engineering, (2004),651-660.

[5]. Feng H., Zhong W., Wu Y., Tong S., "Thermodynamic performance analysis and algorithm model of multipressure heat recovery steam generators (HRSG) based on heat exchangers layout", Energy Convers Manag, (2014), 282-289.
[6]. Durán M.D., Valdés M., Rovira A., Rincón E., "A methodology for the geometric design of heat recovery steam generators applying genetic algorithm". Appl Therm Eng, (2013),77-83.

[7]. Naemi S., Saffar A.M., Behboodi K.S., Mansoori Z., "Optimum design of dual pressure heat recovery steam generator using non-dimensional parameters based on thermodynamic and thermoeconomic approaches" Appl Therm Eng, (2013), 371-384.

[8]. Mohammadi K.A., Joda F., Bozorgmehry R., "Exergic, economic and environmental impacts of natural gas and diesel in operation of combined cycle power plants", Energy Convers Manag, (2016), 103-112.

[9]. Manassaldi J.I., Arias A.M., Scenna N.J., Mussati M.C., Mussati S.F., "A discrete and continuous mathematical model for the optimal synthesis and design of dual pressure heat recovery steam generators coupled to two steam turbines", Energy, (2016), 807823.

[10]. Martelli E., Elsido C., Mian A., Marechal F., "MINLP model and two-stage algorithm for the simultaneous synthesis of heat exchanger networks, utility systems and heat recovery cycles", Comput Chem Eng, (2017), 663-689.

[11]. Pelster S., Favrat D., Von M.R. "The thermoeconomic and environomic modeling and optimization of the synthesis, design, and operation of combined cycles with advanced options", J Eng Gas Turbines Power, (2001),717-726.

[12]. Srinivas T., Gupta A., Reddy B. V., "Thermodynamic modeling and optimization of multi-pressure heat recovery steam generator in combined power cycle" J Sci Ind Res, (2008).

[13]. Hajabdollahi H., Ahmadi P., Dincer I., "An Exergybased multi-objective optimization of a heat recovery steam generator (HRSG) in a combined cycle power plant (CCPP) using evolutionary algorithm" Int J Green Energy, (2011), 44-64.

[14]. Alus M., Petrović M .V., "Optimization of the triplepressure combined cycle power plant",Therm Sci, (2012),901-914.

[15]. Alobaid F., Karner K., Belz J., Epple B., Kim H.G., "Numerical and experimental study of a heat recovery steam generator during start-up procedure", Energy, (2014), 1057-1070.

[16]. Ali M.S., Shafique Q.N., Kumar D., Kumar S., Kumar S., "Energy and exergy analysis of a 747-MW combined cycle power plant Guddu", Int J Ambient Energy, (2018),1-10. 
[17]. Moosazadeh S.A., Mafi M., Kaabi N.A., Salehi G., Torabi A. M. "A new method to boost performance of heat recovery steam generators by integrating pinch and exergy analyses" Adv Mech Eng, (2018).

[18]. Boyaghchi F.A., Molaie H., "Sensitivity analysis of exergy destruction in a real combined cycle power plant based on advanced exergy method" Energy Convers Manag. (2015),374-386.

[19]. Sabia G., Heinze C., Alobaid F., Martelli E., Epple B., "ASPEN dynamics simulation for combined cycle power plant - Validation with hot start-up measurement" Energy, (2019).
[20]. Kakaras E., Doukelis A., Leithner R., Aronis N., "Combined cycle power plant with integrated low temperature heat (LOTHECO)", Applied Thermal Engineering, (2004),1677-1686.

[21]. Balaman Ş.Y., "Uncertainty Issues in Biomass-Based Production Chains", Decision-Making for BiomassBased Production Chains, (2019),77-112.

[22]. Bassily A.M., "Modeling, numerical optimization, and irreversibility reduction of a triple-pressure reheat combined cycle", Energy, (2007),778-794. 